\title{
Musculoskeletal pain and smoking in Norway
}

\author{
Sören Brage, Tor Bjerkedal
}

\begin{abstract}
Objective - To examine the association between musculoskeletal pain and smoking.

Design - Cross sectional, national interview survey.

Setting - All individuals in a representative sample of households in Norway in 1985.

Subjects - A total of 6681 persons aged 16 to 66 years old. People in institutions were not included.

Outcome measures - Gender specific and age specific prevalence rates for pain in the cervical region/upper limbs, back, and lower limbs.
\end{abstract}

Results - Current smoking was independently associated with musculoskeletal pain (odds ratio (OR) $1 \cdot 69 ; 95 \%$ confidence interval (95\% CI) $1 \cdot 45,1 \cdot 97)$ after adjustment for gender, age, comorbidity, mental distress, lifestyle factors, and occupation related factors. The association was of similar strength regarding cervical/upper limb pain (OR $1 \cdot 87$; CI $1 \cdot 56$, $2 \cdot 25)$ and back pain (OR $1 \cdot 84$; CI $1 \cdot 50,2 \cdot 25)$ but weaker in respect of lower limb pain (OR 1·37; CI 1·10,1·71). Musculoskeletal pain was often present in more than one site.

Conclusion - Smoking was significantly associated with musculoskeletal pain after adjustment for other relevant factors.

(f Epidemiol Community Health 1996;50:166-169)

Several epidemiological studies have shown an association between smoking and back pain..$^{1-8}$ A dose-response relationship has also been demonstrated. ${ }^{6-8}$ Two different explanations for this association have been suggested. One is founded on biological causal models, and relates back pain to smoking induced pathological changes in the intervertebral discs. ${ }^{237910}$ The other suggests that the association may be due to confounding by mental distress, low socioeconomic status, occupation, or life style factors. ${ }^{146-81112}$

In recent studies on determinants for neck, shoulder, or leg pain ${ }^{11-13}$ smoking has been suggested as a possible risk factor for pain in other locations. We wished to test, in a large population survey, the hypothesis that smoking is associated with musculoskeletal pain in general. The purpose of the present study was to investigate the association between smoking and musculoskeletal pain in various sites.

\section{Methods}

The Norwegian health survey 1985 was a nationwide interview survey of all members of a representative sample of households. Residents in institutions were not included. Sampling was performed in a two stage design. Finally, 10576 individuals were interviewed from a gross sample of 13438 (response rate $79 \%$ ). ${ }^{14}$ The database of the present study comprises all individuals between 16 and 66 years of age from the data set of the survey $(n=6681)$.

MUSCULOSKELETAL PAIN

In the interview, all subjects were asked about the presence of disease, as well as somatic or mental complaints during the survey period of 14 days. The questions used written descriptions, no pain drawings were included. Three questions were asked to uncover the presence of pain located in the cervical region/ upper limbs (neck, shoulders, arms, or hands), back, or lower limbs (hips or legs). Any episode of pain was considered, by phrasing the questions in the following manner: "Within the last 14 days have you had pain in shoulders, neck, arms, or hands?" In the present study, the responses "not troubled" and "a little troubled" were combined in one category "no pain", and "a lot troubled" and "very much troubled" in a second category "pain". Pain in at least one location was defined as presence of musculoskeletal pain.

\section{INDEPENDENT VARIABLES}

Smoking

We grouped the subjects as current, former, or never smokers. Some seventy six subjects had not responded to questions about smoking and were excluded from further analysis.

\section{Co-morbidity}

Self reported morbidity was coded according to the International Classification of Diseases, 8th revision. In our analysis the presence of nonmusculoskeletal disease (ICD- 8 codes 000 $709,740-753,757-786$, and 788-999) was used as measure of co-morbidity.

\section{Mental distress}

An abridged version of the Hopkin's symptom checklist (HSCL) was used, with 23 questions referring to anxiety and depression. ${ }^{15}$ The subjects were asked to rate the severity of their symptoms on a four point scale from "not at all" (1) to "extremely" (4). The mean score for all questions was used as measure of mental distress. 
Socioeconomic status

All subjects were grouped according to the Norwegian standard for socioeconomic status ${ }^{16}$ and, in our analysis, were aggregated into blue collar workers (unskilled or skilled) and others (salaried employees or self employed).

\section{Type of work and working environment}

The survey enquired about type of work and exposure to noise, polluted air, painful working postures, draughts, and high working speed at the workplace. In the analysis, we categorised the type of work as heavy (physically strenuous or requiring much walking and lifting) or light (mostly sedentary or requiring walking but not lifting), and exposure to workplace factors as considerable (answering "a lot") or slight (answering "a little" or "not at all"). Economically non-active people were categorised as having light work with slight exposure to workplace factors.

Marital status, alcohol consumption, and physical activity during leisure time

These factors were dichotomised into married (including cohabitee) or single; frequent alcohol drinkers (consuming alcohol twice weekly or more) or not frequent drinkers (once per week or less); and physically active (exercise at least once per week) or passive (less than once a week).

\section{STATISTICAL ANALYSIS}

Gender and age specific prevalence rates for musculoskeletal pain among current, former, and never smokers were calculated. $\chi^{2}$ tests were used to determine whether differences between groups were statistically significant at the $5 \%$ level.

Logistic regression models were built to calculate odds ratios for the association between independent variables and pain; $95 \%$ confidence intervals $(95 \% \mathrm{CI})$ were chosen. Multivariate analyses were performed, using forward stepwise variable selection. Variables which did not improve the fit of the model

Table 1 Prevalence of musculoskeletal pain* among current smokers, former smokers and never smokers, based on the Norwegian health survey 1985

\begin{tabular}{|c|c|c|c|c|c|c|c|c|c|}
\hline \multirow[t]{2}{*}{ Age } & \multicolumn{3}{|c|}{ Current smokers } & \multicolumn{3}{|c|}{ Former smokers } & \multicolumn{3}{|c|}{ Never smokers } \\
\hline & Subjects & No & $(\%)$ & Subjects & No & $(\%)$ & Subjects & No & $(\%)$ \\
\hline $\begin{array}{l}\text { Men }(n \\
16-19 \\
20-29 \\
30-39 \\
40-49 \\
50-59 \\
60-66\end{array}$ & $\begin{array}{r}3245) \\
87 \\
272 \\
349 \\
273 \\
227 \\
132\end{array}$ & $\begin{array}{l}10 \\
33 \\
59 \\
51 \\
64 \\
45\end{array}$ & $\begin{array}{l}(11 \cdot 5) \\
(12 \cdot 1) \\
(16 \cdot 9) \\
(18 \cdot 7) \\
(28 \cdot 2) \\
(34 \cdot 1)\end{array}$ & $\begin{array}{r}16 \\
83 \\
185 \\
182 \\
159 \\
163\end{array}$ & $\begin{array}{r}1 \\
12 \\
25 \\
33 \\
29 \\
48\end{array}$ & $\begin{array}{l}(6 \cdot 3) \\
(14 \cdot 5) \\
(13 \cdot 5) \\
(18 \cdot 1) \\
(18 \cdot 2) \\
(29 \cdot 4)\end{array}$ & $\begin{array}{r}228 \\
274 \\
274 \\
169 \\
98 \\
74\end{array}$ & $\begin{array}{r}7 \\
18 \\
27 \\
28 \\
13 \\
17\end{array}$ & $\begin{array}{r}(3.1) \\
(6.6) \\
(9.9) \\
(16.6) \\
(13.3) \\
(23.0)\end{array}$ \\
\hline Total & 1340 & 262 & $(19 \cdot 6)$ & 788 & 148 & $(18 \cdot 8)$ & 1117 & 110 & $(9 \cdot 8)$ \\
\hline $\begin{array}{l}\text { Women } \\
16-19 \\
20-29 \\
30-39 \\
40-49 \\
50-59 \\
60-66\end{array}$ & $\begin{array}{c}n=3360) \\
84 \\
338 \\
357 \\
216 \\
145 \\
101\end{array}$ & $\begin{array}{l}16 \\
71 \\
95 \\
77 \\
56 \\
44\end{array}$ & $\begin{array}{l}(19 \cdot 0) \\
(21 \cdot 0) \\
(26 \cdot 6) \\
(35 \cdot 6) \\
(38 \cdot 6) \\
(43 \cdot 6)\end{array}$ & $\begin{array}{r}21 \\
122 \\
189 \\
111 \\
90 \\
72\end{array}$ & $\begin{array}{r}2 \\
21 \\
35 \\
22 \\
27 \\
33\end{array}$ & $\begin{array}{l}(9 \cdot 5) \\
(17 \cdot 2) \\
(18 \cdot 5) \\
(19 \cdot 8) \\
(30 \cdot 0) \\
(45 \cdot 8)\end{array}$ & $\begin{array}{l}190 \\
289 \\
303 \\
242 \\
261 \\
229\end{array}$ & $\begin{array}{l}19 \\
27 \\
58 \\
47 \\
81 \\
69\end{array}$ & $\begin{array}{r}(10.0) \\
(9.3) \\
(19 \cdot 1) \\
(19 \cdot 4) \\
(31 \cdot 0) \\
(30 \cdot 1)\end{array}$ \\
\hline Total & 1241 & 359 & $(28 \cdot 9)$ & 605 & 140 & $(23 \cdot 1)$ & 1514 & 301 & $(19.9)$ \\
\hline
\end{tabular}

* Reporting cervical/upper limb pain, back pain, and/or lower limb pain during the survey period of 14 days. with a chosen significance level of $5 \%$ were discarded. Age and mental distress were entered as continuous variables, and smoking as a categorical one. Since the effect of smoking might depend on gender and age, the interaction with these factors was calculated, and separate logistic regression models were built for men and women, and for individuals below or above 40 years of age.

To investigate a possible causal effect of pain on smoking, the proportion of former smokers was related to former and current smokers combined, in the groups of subjects with and without pain. Data were processed using SPSS for MacIntosh, version 4.01.

\section{Results}

Altogether $23.9 \%$ (807 of 3374) of the women and $16 \cdot 1 \%$ (523 of 3252) of the men experienced pain in at least one site during the survey period of 14 days. Pain in the cervical region/upper limb was more common $(12.5 \%)$ than back pain $(9.9 \%)$ and lower limb pain $(7 \cdot 7 \%)$. Pain was frequently reported from more than one part of the body: in $50 \%$ of subjects with cervical/upper limb and $66 \%$ of those with back pain or lower limb pain.

\section{SMOKING AND PAIN}

Altogether $41 \cdot 3 \%$ of the men and $36.9 \%$ of the women smoked regularly. Among men, 19.6\% of current smokers reported at least one type of musculoskeletal pain, compared with $9 \cdot 8 \%$ of never smokers $(\mathrm{p}<0.001)$. The corresponding figures for women were $28.9 \%$ and $19.9 \%$, respectively $(\mathrm{p}<0.001)$ (table 1$)$.

When smoking was entered into a logistic regression model adjusted for gender and age, the association between smoking and musculoskeletal pain was noticeable and highly significant, regardless of the localisation of pain (table 2). The odds ratios (OR) for pain among former smokers were intermediary in relation to never and current smokers.

Smoking, gender, age, co-morbidity, mental distress, and exposure to workplace factors contributed significantly and were entered into the model (table 3). Type of work, exposure to draught, socioeconomic group, marital status, alcohol consumption, and physical activity were discarded. The OR for musculoskeletal pain were $1.69(95 \%$ CI $1.45,1.97)$ for current, and $1.22(1 \cdot 02,1 \cdot 47)$ for former smokers.

The associations between smoking and pain in various sites were examined in separate logistic regression models, adjusting for the above factors (data not shown). Current smoking was associated with pain located in the cervical region/upper limbs (OR 1.87; 95\% CI 1.56, $2 \cdot 25)$, back $(1 \cdot 84 ; 1 \cdot 50,2 \cdot 25)$, and lower limbs $(1 \cdot 37 ; 1 \cdot 10,1 \cdot 71)$. There was no significant interaction between smoking and age/gender on pain outcome.

Of those with a history of smoking, $31 \cdot 7 \%$ in the pain group had stopped smoking, compared with $36.1 \%$ in the group without pain $(p<0.05)$. 
Table 2 Association between smoking and musculoskeletal pain among Norwegians aged 16 to 66 years in 1985, calculated as odds ratios (OR), adjusted for gender and age, with 95\% confidence intervals (95\% CI), based on the Norwegian health survey 1985

\begin{tabular}{|c|c|c|c|c|c|c|}
\hline Category & No & $\begin{array}{l}\text { Neck/upper limb } \\
\text { pain } \\
\text { OR }(95 \% \text { CI) }\end{array}$ & $\begin{array}{l}\text { Back pain } \\
\text { OR }(95 \% \text { CI })\end{array}$ & $\begin{array}{l}\text { Lower limb pain } \\
\text { OR }(95 \% \text { CI) }\end{array}$ & $\begin{array}{l}\text { Pain in at least } \\
\text { one site } \\
\text { OR }(95 \% C I)\end{array}$ & $\begin{array}{l}\text { Pain in at least } \\
\text { two sites } \\
\text { OR }(95 \% C I)\end{array}$ \\
\hline $\begin{array}{l}\text { Never smokers } \\
\text { (reference category) }\end{array}$ & 2631 & - & - & - & - & - \\
\hline Former smokers & 1393 & $\begin{array}{l}1 \cdot 28 \\
(1.03,1 \cdot 58)\end{array}$ & $\begin{array}{l}1 \cdot 57 \\
(1 \cdot 25,1 \cdot 98)\end{array}$ & $\begin{array}{l}1 \cdot 10 \\
(0 \cdot 85,1 \cdot 42)\end{array}$ & $\begin{array}{l}1 \cdot 34 \\
(1 \cdot 13,1 \cdot 59)\end{array}$ & $\begin{array}{l}1 \cdot 35 \\
(1 \cdot 04,1 \cdot 75)\end{array}$ \\
\hline Current smokers & 2581 & $\begin{array}{l}2 \cdot 03 \\
(1 \cdot 71,2 \cdot 42)\end{array}$ & $\begin{array}{l}2 \cdot 02 \\
(1 \cdot 67,2 \cdot 46)\end{array}$ & $\begin{array}{l}1 \cdot 46 \\
(1 \cdot 18,1 \cdot 82)\end{array}$ & $\begin{array}{l}1 \cdot 86 \\
(1 \cdot 61,2 \cdot 15)\end{array}$ & $\begin{array}{l}1 \cdot 92 \\
(1.55,2 \cdot 39)\end{array}$ \\
\hline
\end{tabular}

\section{Discussion}

Using data from a large, cross sectional interview survey in Norway, relatively strong associations between smoking and musculoskeletal pain in various sites were found, after adjusting for confounding variables. Other studies ${ }^{4813}$ have reported adjusted OR for back pain among smokers in the range $1 \cdot 4-1 \cdot 5$, that is, results close to ours.

Our findings suggest that smoking is associated with both neck pain and back pain. In other studies, the association with neck disorders have been inconsistent. ${ }^{112}$ Smoking was also associated with pain in lower limbs, supporting recent findings by Boshuizen et al. ${ }^{1}$

In the national health survey 1985 , nonresponse bias was small and hardly of any practical importance ${ }^{14}$ By using a short survey period of 14 days, the impact of recall bias on the validity and reliability of data is probably of little importance. ${ }^{17}$ The reported prevalence of musculoskeletal pain was lower than in other Scandinavian studies, ${ }^{18-20}$ probably because individuals more than 67 years old or living in institutions were excluded from our study.

\section{CONFOUNDING}

The association between smoking and pain remained significant when mental distress was entered into the multivariate model. The HSCL has been tested thoroughly. ${ }^{15}$ In the Norwegian health survey, however, the original HSCL was amended and used in interviews, making it susceptible to bias and interviewer effects. It seems unlikely, though, that reporting of pain or smoking was systematically biased.

Table 3 Association between risk factors and self reported musculoskeletal pain* among Norwegians aged 16 to 66 years in 1985. Odds ratios, adjusted for gender, age, nonmusculoskeletal disease, mental distress, workplace factors, and smoking, with 95\% confidence intervals $(95 \%$ CI), based on the Norwegian health survey 1985.

\begin{tabular}{|c|c|c|c|}
\hline \multirow[b]{2}{*}{ Category } & \multicolumn{3}{|c|}{ Musculoskeletal pain in at least one part } \\
\hline & No of subjects & OR & $95 \% C I$ \\
\hline \multicolumn{4}{|l|}{ Gender: } \\
\hline Male (reference category) & 3245 & & \\
\hline $\begin{array}{l}\text { Female } \\
\text { Age per each additional year }\end{array}$ & 3360 & $\begin{array}{l}1.89 \\
1.03\end{array}$ & $\begin{array}{l}1 \cdot 64,2 \cdot 17 \\
1 \cdot 03,1 \cdot 04\end{array}$ \\
\hline Reporting non-musculoskeletal disease & 3227 & 1.86 & $1 \cdot 63,2 \cdot 13$ \\
\hline $\begin{array}{l}\text { Mental distress per each additional } \\
\text { point } \dagger\end{array}$ & & 1.58 & $1 \cdot 39,1 \cdot 80$ \\
\hline \multicolumn{4}{|l|}{ Workplace factors: } \\
\hline $\begin{array}{l}\text { Noise } \\
\text { Polluted air }\end{array}$ & 610 & $\begin{array}{l}0.76 \\
1.48\end{array}$ & $\begin{array}{l}0.59,0.98 \\
1.15\end{array}$ \\
\hline $\begin{array}{l}\text { Polluted air } \\
\text { Painful working postures }\end{array}$ & $\begin{array}{l}521 \\
495\end{array}$ & 2.97 & $2 \cdot 37,3 \cdot 73$ \\
\hline Stress & 1081 & $1 \cdot 43$ & $1 \cdot 20,1 \cdot 71$ \\
\hline Never smokers (reference category) & 2631 & & \\
\hline Former smokers & 1393 & $1 \cdot 22$ & $1 \cdot 02,1 \cdot 47$ \\
\hline Current smokers & 2581 & 1.69 & $1 \cdot 45,1 \cdot 97$ \\
\hline
\end{tabular}

* Reporting cervical/upper limb pain, and/or lower limb pain during the survey period of 14 days † For instance, increasing mean score of the abridged version of the Hopkin's symptom checklis from 1.00 to $2 \cdot 00$.
Lower socioeconomic status is associated with smoking and musculoskeletal pain, ${ }^{19-21}$ and status associated factors, such as physical job demands or life style, have been claimed to act as confounders. ${ }^{146}$ In the present study, lower status and status related factors were separately associated with musculoskeletal pain. However, when entered into multivariate models, their impact on the association between smoking and pain was small. Socioeconomic status was only weakly associated with pain, in accordance with findings by Croft and Rigby. ${ }^{4}$ One reason might be that current classifications of status do not capture the social dimensions that influence the association between pain and smoking.

Recording of workplace factors was based on subjective statements. People suffering from pain probably wish to find external causes for example working postures - behind their troubles. These mechanisms of attribution would exaggerate the association with workplace factors but not affect the association between pain and smoking. Higher alcohol consumption and lack of physical activity did not confound the association between smoking and musculoskeletal pain.

The present study cannot, however, exclude confounding by other variables we have not examined. Risk factors that were not measured by our instruments, and linked, for example, to social class or mental distress, could be associated with both smoking and pain and cause a spurious relationship.

\section{A CAUSAL RELATIONSHIP?}

In cross sectional studies temporal relations between smoking and pain cannot be established conclusively but it seems probable that smoking precedes pain. One study has shown that the age of beginning smoking usually antedates back pain. ${ }^{6}$ Furthermore, ill health is probably a poor incentive to start smoking, although patients with chronic pain are known to increase their smoking when they have pain. ${ }^{22}$ In our study, however, people with pain did not stop smoking as often as those without pain. Such selection could gradually add more pain ridden individuals to the pain/ smoking group. On the other hand, since the group of former smokers had significantly more pain than never smokers, there is reason to assume that this selection effect was very small.

The significant association between smoking and pain of various localisation, can, in our opinion, generate two different hypotheses. 
Smoking might have a more general effect on the musculoskeletal system. Smoking induced blood flow reduction, hypoxia, or chemical changes might lead to degeneration in muscles, joints, and discs. Alternatively, a central, nervous effect might be involved. It might be hypothesised that nicotine, through its excitatory effects, alters the perception and threshold for pain, increasing self reporting of pain among smokers.

\section{Conclusion}

Smoking was significantly associated with musculoskeletal pain, after adjustment for gender, age, co-morbidity, mental distress, lifestyle factors, and occupation related factors. Smoking might be a contributory cause of musculoskeletal pain.

1 Boshuizen HC, Verbeek JHAM, Broersen JPJ, Weel ANH Do smokers get more back pain? Spine 1993;18:35-40.

2 Ernst E. Smoking, a cause of back trouble? Br $\mathcal{F}$ Rheumatol 1993;32:239-42.

3 Battié MC, Videman T, Gill K, et al. Smoking and lumbar intervertebral disc degeneration: an MRI study of identical intervertebral disc degeneration
twins. Spine 1991;16:1015-21.

4 Croft PR, Rigby AS. Socioeconomic influences on back problems in the community in Britain. $\mathcal{F}$ Epidemiol Comproblems in the community in
munity Health 1994;48:166-70.

5 Biering-Sørensen FB, Thomsen C. Medical, social and occupational history as risk indicators for low-back trouble in a general population. Spine 1986;11:720-5.

6 Deyo RA, Bass JE. Lifestyle and low-back pain. The in fluence of smoking and obesity. Spine 1989;14:501-6.

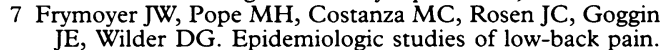
Spine 1980;5:419-23.
8 Heliövaara $M$, Mäkelä $M$, Knekt $P$, Impivaara $\mathrm{O}$, Aromaa A. Determinants of sciatica and low-back pain. Spine 1991;16:608-14

9 Kelsey JL. An epidemiological study of acute herniated lumbar intervertebral discs. Rheumatol Rehabil 1975;14: 144-59.

10 Holm S, Nachemson A. Nutrition of the intervertebral disc: acute effects of cigarette smoking. Uppsala $\mathcal{F}$ Med Sci 1988; 93:91-9.

11 Mäkelä $M$, Heliövaara $M$, Sievers $K$, Impivaara O, Knekt P, Aromaa A. Prevalence, determinants and consequences of chronic neck pain in Finland. Am $\mathcal{f}$ Epidemiol 1991 134:1356-67.

12 Ekberg K, Björkqvist B, Malm P, Bjerre-Kiely B, Karlsson $\mathrm{M}$, Axelson $\mathrm{O}$. Case-control study of risk factors fo disease in the neck and shoulder area. Occup Environ Med 1994;51:262-6.

13 Tsai SP, Gilstrap EL, Cowles SR, Waddell LC, Ross CE. Personal and job characteristics of musculoskeletal injuries in an industrial population. $\mathcal{F}$ Occup Med 1992;34:606-12.

14 Norges offisielle statistikk. Health Survey 1985. Oslo: Central Bureau of Statistics, 1987.

15 Derogatis LR, Lipman RS, Rickels K, Uhlenhuth EH, Covi L. The Hopkins symptom checklist (HSCL): a self-report symptom inventory. Behav Sci 1974;19:1-15.

16 Standarder for norsk statistikk. Standard for inndeling etter sosioøkonomisk status. (Standard classification of socioeconomic status). Oslo: Central Bureau of Statistics, 198 (in Norwegian).

17 Raspe H, Kohlmann T. Disorders characterised by pain: a methodological review of population surveys. $\mathcal{f}$ Epidemio Community Health 1994;48:531-7.

18 Natvig B, Nessiøy I, Bruusgaard D, Rutle O Musculoskeletal symptoms in a local community. European fournal of General Practice 1995;1:25-8.

19 Bredkjær SR. Musculoskeletal disease in Denmark. The Danish Health and Morbidity Survey 1986-87. Acta Orthop Scand 1991;62 (suppl 241):10-2.

20 Andersson I, Ejlertsson G, Leden I, Rosenberg C. Chronic pain in a geographically defined general population: studies in differences in age, gender, social class and pain localization. Clinical fournal of Pain 1993;9:174-82.

21 Mackenbach JP. Socio-economic health differences in the Netherlands: a review of recent empirical findings. Soc $S c$ Med 1992;34:213-26.

22 Jamison RN, Stetson BA, Parris WC. The relationship between smoking and chronic low back pain. Addict Behav 1991;16:103-10. 